\title{
Framingham Foot Assessment Clinical Tool
}

National Cancer Institute

\section{Source}

National Cancer Institute. Framing ham Foot Assessment Clinical Tool. NCl Thesaurus.

Code C153301.

A research tool designed to assess foot pain and relate it to footwear. 